\title{
Information Organization Patterns from Online Users in a Social Network ${ }^{\dagger}$
}

\author{
Chengzhi Zhang*, Hua Zhao**, Xuehua Chi*** and Shuitian Ma**** \\ Nanjing University of Science and Technology, Department of Information Management, \\ Nanjing, 210094, China, \\ *<zhangcz@njust.edu.cn>,**<joyce.chi@qq.com>, ***<1249662620@qq.com>, \\ ****<mashutian0608@hotmail.com>
}

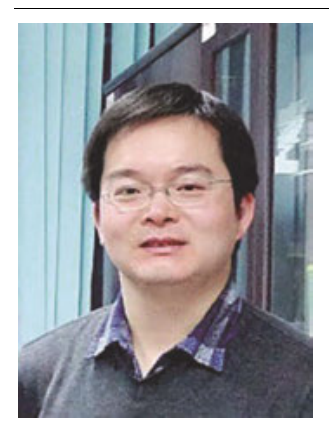

Chengzhi Zhang is Professor of information science in the Department of Information Management, Nanjing University of Science and Technology. He is a also visiting scholar at the University of Pittsburgh, Pittsburgh (2013) and Senior Research Associate at the City University of Hong Kong, Hong Kong SAR (2010 2011). His research interests are information organization, digital libraries, information retrieval, text mining, natural language processing, etc. He has published approximately 100 articles in refereed journals and conference proceedings including JASIST, ASLIB JIM, OIR, Scientometrics, etc. He is an editorial advisory board member of The Electronic Library, Data Intelligence and Technology Intelligence Engineering.

Hua Zhao received her master's degree in information science as well as bachelor's degree in information management and system program from the Nanjing University of Science and Technology, Nanjing, China, in 2014 and 2017, respectively. From 2018, she joined as an algorithm engineer with the Ctrip.com International Ltd, Shanghai, China. Her research interests include text mining and natural language processing.

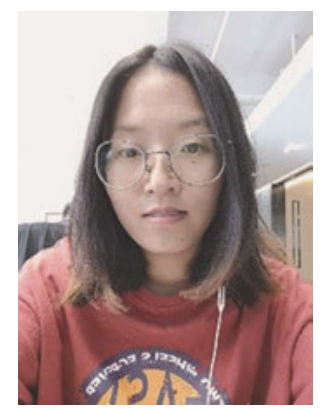

Xuehua Chi is a graduate student at Nanjing University of Science and Technology. She received her bachelor's degree in information management and information system from Nanjing University of Science and Technology as well. Her research interests include user modeling, text mining, information systems, and knowledge organization.

Shutian Ma is a doctoral student at Nanjing University of Science and Technology. She is in the last year of a master-doctor combined program now and received her bachelor's degree in information management and information system from Nanjing University of Science and Technology as well. Her research interests include citation recommendation, embedding algorithms, clustering and classification, and knowledge organization.

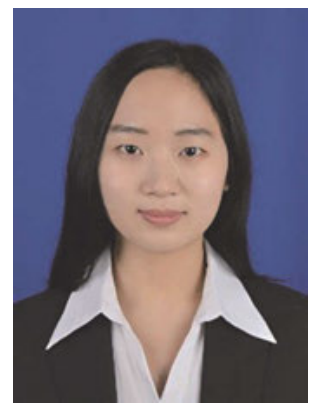

Zhang, Chengzhi, Hua Zhao, Xuehua Chi and Shuitian Ma. 2019. "Information Organization Patterns from Online Users in a Social Network." Knowledge Organization 46(2): 90-103. 37 references. DOI:10.5771/0943-74442019-2-90.

Abstract: Recent years have seen the rise of user-generated contents (UGCs) in online social media. Diverse UGC sources and information overload are making it increasingly difficult to satisfy personalized information needs. To organize UGCs in a user-centered way, we should not only map them based on textual topics but also link them with users and even user communities. We propose a multi-dimensional framework to organize information by connecting UGCs, users, and user communities. First, we use a topic model to generate a topic hierarchy from UGCs. Second, an author-topic model is applied to learn user interests. Third, user communities are detected through a label propagation algorithm. Finally, a multi-dimensional information organization pattern is formulated based on similarities among the topic hierarchies of UGCs, user interests, and user communities. The results reveal that: 1) our proposed framework can organize information from multiple sources in a user-centered way; 2) hierarchical topic structures can provide comprehensive and in-depth topics for users; and, 3) user communities are efficient in helping people to connect with others who have similar interests.

Received: 3 June 2018; Sixth revision: 17 January 2019; Accepted: 18 January 2019

Keywords: topic model, user, information, social networks

† This work is supported by the National Social Science Fund (No. 14BTQ033), Key Laboratory of Richmedia Knowledge Organization and Service of Digital Publishing Content, Institute of Scientific and Technical Information of China (No. ZD2018-07/01) and Qing Lan Project. 


\subsection{Introduction}

Various online social networks have been created for people to communicate and share information with each other around the world. There is also increasing growth in the numbers of social media users. For example, at the end of September 2017, Twitter had 330 million active monthly users (https://www.statista.com/statistics/282087/num ber-of-monthly-active-twitter-users/), while Sina Weibo (https://weibo.com), one of the biggest Chinese microblog platforms, had 376 million active monthly users (http://www.useit.com.cn/thread-17562-1-1.html). Simultaneously, vast quantities of user-generated contents (UGCs), referring to images, videos, text, audio, and any other form of content, are being posted by users in online platforms (https://en.wikipedia.org/wiki/User-generated _content). Due to their huge volume, uneven quality, and dynamic changes, UGCs pose new challenges for mining and organizing content (Zhu et al. 2013, 233).

To provide organized information for users, most of the current social networks methodically present UGCs. For instance, Sina Weibo displays posts in chronological order, whereas users may prefer contents to be sorted by topics of their interests. There are a large number of redundant communities and inactive groups in social networks, since most cannot organize information efficiently to meet users' needs (Treem and Leonardi 2012, 143). Researchers are seeking ways to group and streamline large amounts of UGCs (Kietzmann et al. 2011; Van Damme et al. 2007). Traditional knowledge organization tools employ conventional relations between concepts, subjects, and information units, whereas current studies focus more on users, aiming to organize and integrate information in a user-centered way (Hjørland 2003; 2014).

There are three indispensable elements of a social network platform: UGCs, users, and user communities. Since most related research is focused on one element in attempting to organize information (Ming et al. 2014; Zhu et al. 2014), we aim to develop a multi-dimensional information organization system by linking the three elements. To represent UGCs, we employ a topic model to construct a topic hierarchy, which has been widely used in many studies (Zhang 2017; Zhu et al. 2013; Zhu et al. 2014). We then generate profiles of users' interests through user modeling and detect community structure to reveal network organization of users. Finally, to support user-centered information organization, we perform similarity calculations to associate UGCs, users, and user communities with one another.

\subsection{Related works}

Of the rich set of studies on the organization of online information organization, in this section we discuss mainly research into UGCs and user information behavior.

\subsection{Information organization based on UGCs}

With the popularization of web 2.0, UGCs have received much attention from researchers. Social tags and folksonomies are becoming popular among different types of UGCs (Kim 2008). Researchers have made particular progress on information organization (Munk and Mørk 2007). Noruzi and Alireza (2006) explored the folksonomy tagging phenomenon and discussed relevant problems. Mathes (2004) provided the first review and survey of social tagging systems. Potnis $(2011,32-35)$ allowed users to participate in information organization by using folksonomy. Finally, Van Damme et al. (2007) proposed an integrated approach for turning folksonomies into ontologies and using networked knowledge organization systems for information organization.

While mass UGCs provide rich information resources, they also present new challenges, like the integration of heterogeneous contents. Although classifying UGCs in pre-customized categories is simple, classification accuracy depends on the manual maintenance of a category system (Gao 2012, 761). Chen et al. (2011) organized UGCs through a topic model, which does not require maintenance of a classification system. However, the topics obtained from their model were somewhat difficult to understand, and its classification accuracy needs to be improved. Gupta et al. (2010) used social labels for information organization, which greatly reduces manual costs, but their method has problems of data sparseness due to label scarcity. Zhu et al. (2013) proposed topic hierarchy construction for UGCs, while Li (2013) constructed the hierarchical architecture in an entity-based formalism. These studies are very relevant but do not distinguish between different types of UGCs, and few studies have attempted multi-dimensional information organization.

\subsection{Information organization based on user information behavior}

The research related to user information behavior can be divided into theoretical and empirical works. Theoretical research has explored, for instance, the behavior of information query (Bawden 2006), information interaction (Chen et al. 1998; Keenan et al. 2013), information creation (Maria et al. 2008), information utilization (Kaplan et al. 2010), and information sharing (Stutzman 2006). Empirical research has mainly focused on information behav- 


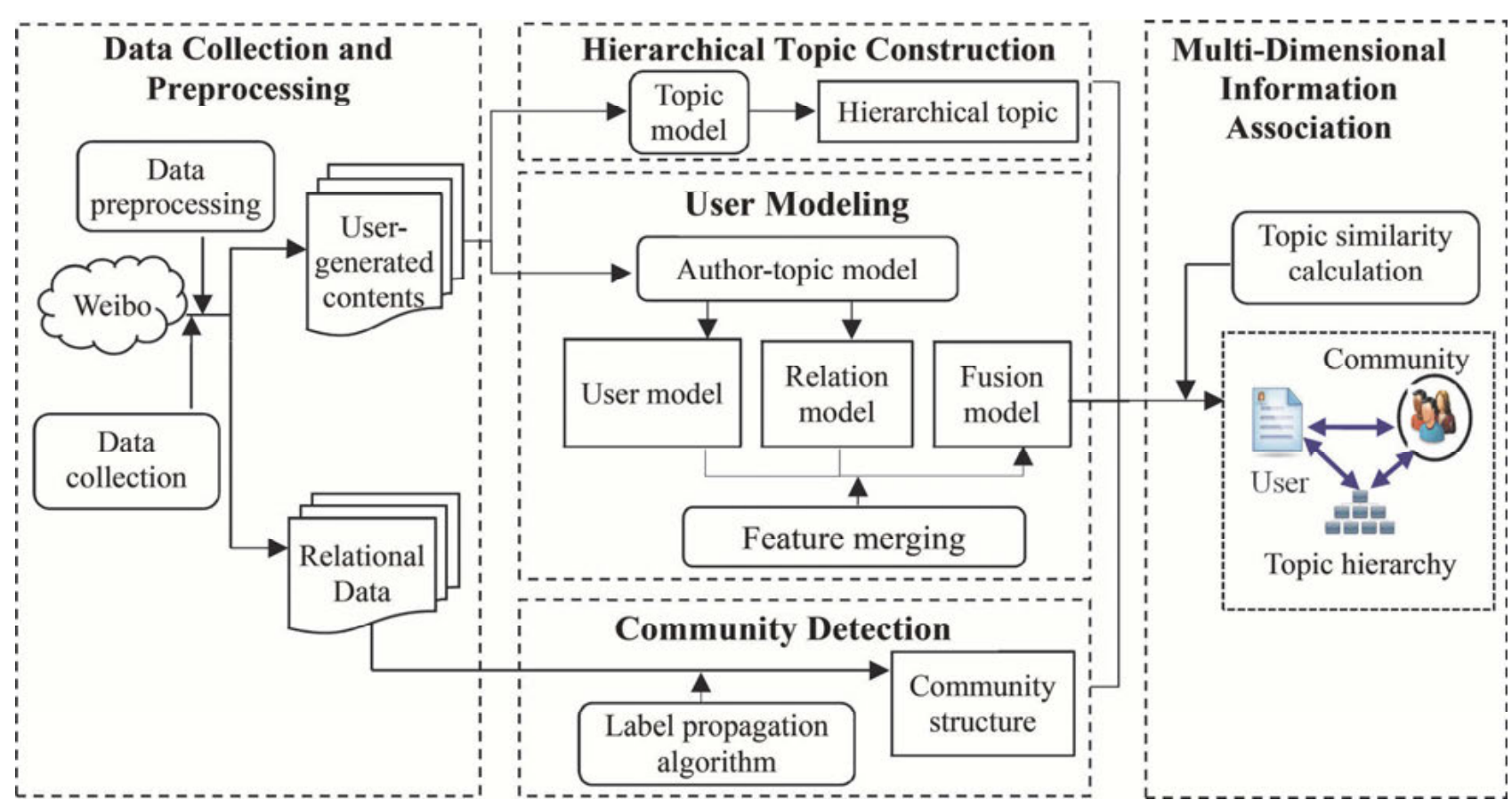

Figure 1. Framework of the study's multi-dimensional information organization.

ior (Benevenuto et al. 2009), user influence (Agichtein et al. 2008), and user social relationships (Kwak et al. 2010). Overall, few studies have explored user behavior with respect to organizing information. Bar-Ilan and Belous (2007) studied the theory and practice of information organization and its relationship with human perception, proposing an intuitive information organization system. Bu et al. (2010) emphasized the importance of considering user behavior, participation, and experience when designing an information organization interface. There is clearly a need for more in-depth research of user behavior, especially with respect to organizing information on social networks.

Traditional methods of information organization rely on semantic or topical relations between textual contents to organize UGCs, without considering the users who generate contents and the user communities in which similar users gather. Despite the increasing shift toward user-centered information integration (Zhou 2010, 36-40), focusing especially on relationships between information and users, only a few studies have considered a multi-dimensional approach to organizing information, combining UGCs with users and user communities. By fully considering the features of UGCs, this study endeavors to associate these three elements to generate a new pattern of knowledge organization in social networks.

\subsection{Methodology}

\subsection{Framework}

To connect UGCs, users, and user communities, we attempt to map them in a topic space. Our framework comprises four main steps: 1) hierarchical topic construction for UGCs; 2) user modeling to represent user interests; 3) community detection; and, 4) multi-dimensional information association to link UGCs, users, and user communities. Our experimental process is depicted in Figure 1.

We begin by collecting UGCs from verified users' microblogs and the relationships between users in five domains (football, internet, literature, medicine, law) on Sina Weibo. We then use these UGCs (taken from posts that users create, like, and repost) to generate the topic hierarchy. To obtain a fusion model of users, we merge features learned from users' interests and relations (follower, following) using an author-topic model. To detect user communities, we employ a label propagation algorithm. Finally, a multi-dimensional information organization system is constructed by calculating topic similarities among the UGC topic hierarchy, the user fusion model, and detected user communities.

In the next section, we will discuss the key techniques employed in UGC topic hierarchy construction, user modeling, community detection, and multi-dimensional information association. 


\subsection{Key techniques}

\subsubsection{UGC topic hierarchy construction}

\subsubsection{Latent Dirichlet Allocation (LDA)}

LDA is a three-level hierarchical Bayesian model (Blei et al. 2003). It assumes that each item in a collection is generated by the finite mixture of topics, each of which is modeled as a multinomial mixture of vocabulary. It also assumes that each document is modeled as a finite mixture over an underlying set of topics. The topic mixture is then drawn from a conjugate Dirichlet prior that remains the same for all documents. The LDA model contains the following parameters: $a$, the Dirichlet priori parameter of document-topic distribution; $\beta$, the Dirichlet prior parameter of topic-word distribution; $K$, the topic number; $d$, the document; and $\%$ the topic. This paper uses the LDA model to derive topical representations for verified users in the five domains of law, medicine, literature, football, and internet.

\subsubsection{Document topic extraction}

After topic modeling, each document is projected into the topic space with different probability distributions, as shown in equation 1 below. We then set a threshold to assign a specific topic to each document; if the topic probability of a document in the topic space exceeds the predefined threshold, the document is assigned to this topic.

$$
\begin{aligned}
& \text { doc }_{i}=\left\{\text { topic }_{1}: w_{i, 1}, \text { topic }_{2}: w_{i, 2}, \ldots,\right. \\
& \text { topic } \left._{j}: w_{i, j}, \ldots, \text { topic }_{n}: w_{i, n}\right\}
\end{aligned}
$$

Where topic $_{j}$ represents topic $j, d o c_{i}$ represents document $i, w_{i, j}$ represents the weight of topic $j$ in document $\mathrm{i}$. $w_{i, 1}+w_{i, 2}+\cdots+w_{i, j}+\cdots+w_{i, n}=1, p=1 / n ;$ if $w_{i, j}>$ $p$, we assign this document to topic $_{j}$, thereby collecting the documents for each topic.

\subsubsection{User modeling}

\subsubsection{Author-topic model}

The author-topic model uses a topic-based representation to model both document contents and author interests. This model supposes that each author has a topic probability distribution $\theta$, and each topic has a term probability distribution $\varphi$, as shown in Figure 2. The model generation process (Steyyers et al. 2004, 307-310) is as follows:

1) Extract the polynomial probability distribution $\theta$ for each author;
2) Extract the polynomial probability distribution $\varphi$ for each topic;

3) For each item in document $d$ :
a) extract an author $x$;
b) extract a subject $z$
c) extract a term $w$;

4) Repeat extraction $N_{d}$ times to generate document d.

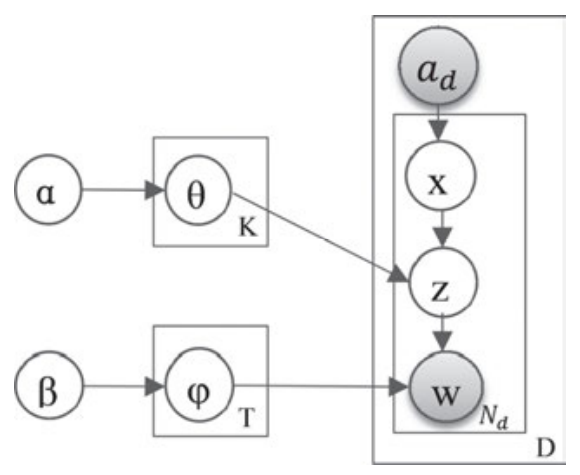

Figure 2. Author-topic model.

In the author-topic model: $\theta$ represents the author-topic probability distribution; $\varphi$ represents the topic-term probability distribution; $a$ is the Dirichlet prior parameter of document-topic probability distribution; $\beta$ is the Dirichlet prior parameter of the topic-term probability distribution; $\underline{a}_{\mathrm{d}}$ represents the uniform distribution of the author's set; $x$ represents the author; $z$ represents the topic; $w$ is the term; $D$ represents the document set; $N_{d}$ represents the number of repeated samples; $K$ represents the number of authors; and $T$ represents the number of topics.

\subsubsection{User fusion model}

After first using author-topic data to model user interests using posts in five domains, we then used relational data collected on followers and followings to generate follower collection model and following collection model by the author-topic model. Finally, the fusion model is obtained by fusing the three models (user model, follower collection model, and following collection model).

User model of each user is denoted as equation 2:

$u=\left\{\begin{array}{c}\text { topic }_{1}: w_{1}, \ldots, \text { topic }_{i}: w_{i}, \ldots, \\ \text { topic }_{n}: w_{n}\end{array}\right\}$ (equation 2)

Where, $w_{1}+\cdots+w_{i}+\cdots+w_{n}=1, u$ represents the user model, topic $c_{i}$ represents topic $i$, and $w_{i}$ represents the weight of topic $i$.

With reference to Hannon (2010, 201), the follower collection and following collection model are obtained by merging the follower model and the following model separately, which are complemented to the user model by the following equation: 
$U_{\text {all }}=\left\{\begin{array}{c}\left.u_{\text {self }}: w_{\text {self }}, \mathrm{U}_{\text {followers }}: w_{\text {followers }}\right) \\ \mathrm{U}_{\text {followings }}: w_{\text {followings }}\end{array}\right\}($ equation 3)

Where, $w_{\text {self }}+w_{\text {followers }}+w_{\text {followings }}=1 ; u_{\text {self }}$ represents the user model; $\mathrm{U}_{\text {followers }}$ represents the followers collection model; $\mathrm{U}_{\text {followings represents the follow- }}$ ings collection model; $w_{\text {self }}$ represents the weight of the user model; $w_{\text {followers }}$ represents the weight of the followers collection model; $w_{\text {followings }}$ represents the weight of the following collection model; and $U_{\text {all }}$ represents the final user model, also called the user fusion model. $U_{\text {followers }}$ and $U_{\text {followings }}$ is computed by the following formula:

$\mathrm{U}=\sum_{i=1}^{N} u_{i}$

(formula 1)

Where $u_{i}$ represents user $i$ 's own model, and $\mathrm{U}$ represents the model results of user collection $\left\{u_{1}, \ldots, u_{i}, \ldots, u_{N}\right\}$.

\subsubsection{User community detection}

\subsubsection{Label propagation algorithm}

The label propagation algorithm (Raghavan et al. 2007) is the classical algorithm for finding communities and is widely used in large-scale networks. The algorithm assumes that a node's label is the one carried by the largest number of its neighbors. Nodes with the same label are grouped into the same community. The steps of the label propagation algorithm are as follows:

1) Initialize the labels of all nodes in the network, and give each node a unique label;

2) Set $t=1$, with $t$ representing the number of iterations;

3) Randomly arrange nodes in the network, and generate sequence $\mathrm{X}$;

4) According to the order in sequence $X$, let each node's label be $\arg _{\mathrm{N}^{\mathrm{l}}(\mathrm{v})}^{\max }$, where $\mathrm{N}^{\mathrm{l}}(\mathrm{v})$ represents the set of neighbors with label $\mathrm{v}$;

5) Update labels until each node changes its label to the one carried by the largest number of its neighbors; set $\mathrm{t}=\mathrm{t}+1$, and return to the third step.

Through this repeated process, nodes with the same label are grouped into the same community.

\subsubsection{Community detection}

Modularity is a benefit function that measures the quality of a network's division into groups or communities (Newman et al. 2004). The formula is:

$\mathrm{Q}=\frac{1}{2 m} \sum_{i j}\left(A_{i j}-P_{i j}\right) \delta\left(C_{i}, C_{j}\right)$

(formula 2)
Where $A_{i j}$ represents the adjacency matrix of the network graph; $m$ represents the number of edges of the network graph; and $P_{i j}$ represents expectations of the edge between node $i$ and node $j$ in an empty model. Networks with high modularity have dense connections between the nodes within modules but sparse connections between nodes in different modules. If nodes $i$ and $j$ are in the same community, $\delta\left(C_{i}, C_{j}\right)=1$; otherwise, $\delta\left(C_{i}, C_{j}\right)=0$.

\subsubsection{Multi-dimensional information association}

We use the Jensen-Shannon (JS) divergence distance to calculate the similarity of topics, based on the "topic-term" matrix obtained from the user model and topic model. The formula of the JS divergence distance is as follows:

$D_{J S}(P \| Q)=1 / 2\left(\sum_{i} \ln \left(\frac{P(i)}{Q(i)}\right) P(i)+\right.$
$\left.\sum_{i} \ln \left(\frac{Q(i)}{P(i)}\right) Q(i)\right)$

(formula 3)

Where $P(i)$ represents the probability of word $i$ in topic $\mathrm{P}$, and $\mathrm{Q}(i)$ represents the probability of word $i$ in topic Q.

We can then calculate the similarity among hierarchy topics, users, and user communities to build a multi-dimensional information organization system.

\subsection{Experiment}

\subsection{Dataset}

For this study, we collected 4,966 verified users from Sina Weibo. Microblogs were sourced from Tu et al. (2015). The maximum number of microblogs was set to 500 for each specific user. In total, there are 1,887,633 user post profiles across the five domains, as elaborated in Table 1.

In addition, 152,976 follower and following relationships were crawled. As Table 2 shows, we obtain 106,388 pairs of followers and 110,367 pairs of following, and there are fewer follower-following pairs than the sum of follower and following pairs, which indicates that existing user pairs follow each other.

\subsection{Experimental results analysis}

\subsubsection{UGC topic hierarchy construction}

LDA is used to derive the first topic layer using the open source Gibbs sampling tool. The parameters are set as follows (see Section 3.2.1 for parameter definitions): $K=5$, $a$ $=50 / K$, and $\beta=0.01$. Document collections for each 
Chengzhi Zhang, Hua Zhao, Xuehua Chi and Shuitian Ma. Information Organization Patterns from Online Users in a Social Network

\begin{tabular}{|c|c|c|c|c|c|c|}
\hline domain & football & internet & law & literature & medicine & Total \\
\hline posts & 409,389 & 393,187 & 201,477 & 655,816 & 227,764 & $\mathbf{1 , 8 8 7 , 6 3 3}$ \\
\hline
\end{tabular}

Table 1. Microblogs distribution across different domains.

\begin{tabular}{|c|c|c|c|}
\hline Relationship type & Follower & Following & Follower + following \\
\hline pairs & 106,388 & 110,367 & 152,976 \\
\hline
\end{tabular}

Table 2. Relational data distribution.

\begin{tabular}{|c|c|c|c|c|c|c|c|}
\hline \multicolumn{2}{|c|}{ User model } & \multicolumn{2}{c|}{ Following model } & \multicolumn{2}{c|}{ Follower model } & \multicolumn{2}{c|}{ Fusion model } \\
\hline Topic0 & 0.3527 & Topic0 & 0.3391 & Topic0 & 0.2526 & Topic0 & 0.3300 \\
\hline Topic19 & 0.1875 & Topic19 & 0.1339 & Topic19 & 0.1378 & Topic19 & 0.1669 \\
\hline Topic47 & 0.1070 & Topic3 & 0.0560 & Topic36 & 0.0752 & Topic47 & 0.0864 \\
\hline Topic26 & 0.0970 & Topic47 & 0.0551 & Topic47 & 0.0558 & Topic26 & 0.0772 \\
\hline Topic3 & 0.0664 & Topic10 & 0.0481 & Topic3 & 0.0527 & Topic3 & 0.0616 \\
\hline Topic18 & 0.0382 & Topic26 & 0.0480 & Topic26 & 0.0471 & Topic18 & 0.0318 \\
\hline Topic13 & 0.0259 & Topic36 & 0.0463 & Topic10 & 0.0440 & Topic36 & 0.0261 \\
\hline
\end{tabular}

Table 3. Model results based on user and relationship data

topic are extracted by document extraction method. We set the topic probability threshold to $1 / K(0.2)$ and get five new document collections. Subsequently, we use LDA to derive the second topic layer based on these five new collections of documents. By repeating the last steps, we derive the third topic layer, thus completing the UGC topic hierarchy structure, in which the first, second, and third hierarchical layers comprise five, twenty-five, and 125 topics, respectively. The Appendix presents the ten mostcommon terms for each topic, together with their probabilities.

As shown in the Appendix, the first-layer topics are "literature," "law," "medicine," "football," and "internet"; the second-layer topic terms for the first-layer topic "medicine" are "experts," "daily recuperation," "surgical," "female medical treatment," and "diet"; the third-layer topic terms for the second-layer topic of "female medical treatment" are "pregnancy," "diseases of affluence," "treatment," "nursery," and "pregnancy test." The third topic layer is the fine-grained description of the first topic layer, showing the hierarchical relationship and distribution of topics in each level.

\subsubsection{User modeling}

Each user is modeled based on microblogs and relationships. We applied author-topic modeling (ATM) to formulate the user model using microblogs. The ATM parameters are set as follows (see Section 3.2.2 for parameter definitions): $K=50, \alpha=50 / K$, and $\beta=0.01$. We also generate the follower collection model and following collection model for each user by merging user's each follower's posts and following's posts respectively. Note that the follower model and following model are normalized in this study. Finally, the user fusion model is formed by integrating the user, follower, and following models, respectively weighted $0.6,0.2$, and 0.2 .

To demonstrate the process, we choose user "178****763" on Sina Weibo, who has a large number of followers. As Table 3 shows, the high-frequency topics of the user model, follower collection model, and following collection model for this individual are "Topic0," "Topic19," "Topic47," "Topic26," and "Topic3." The only difference between the follower model and following model is found in the topics' weights. Compared to the 
Chengzhi Zhang, Hua Zhao, Xuehua Chi and Shuitian Ma. Information Organization Patterns from Online Users in a Social Network

\begin{tabular}{|c|c|c|c|}
\hline 训练 (Training) & $\begin{array}{l}\text { 足球赛事 (Football game) } \\
\text { Topic 19: }\end{array}$ & 人生感悟 (Life thoughts) & 家庭 (Family) \\
\hline Topic0: & 足球 (football) 0.0368 & Topic47: & Topic26: \\
\hline 加油 (Fighting) 0.0257 & 比赛 (competition) 0.0205 & 人生 (life) 0.0219 & 孩子 (child) 0.0090 \\
\hline 比赛 (competition) 0.0241 & 俱乐部 (club) 0.0089 & 生活 (living) 0.0207 & 妈妈 (mother) 0.0061 \\
\hline 足球 (Football) 0.0142 & 联赛 (league) 0.0059 & 世界 (world) 0.0133 & 回家 (go home) 0.0047 \\
\hline 兄弟 (brother) 0.0126 & 冠军 (champion) 0.0053 & 生命 (live) 0.0085 & 儿子 (son) 0.0046 \\
\hline 训练( training) 0.0112 & 国安 (Guoan) 0.0049 & 梦想 (dream) 0.0067 & 爸爸 (father) 0.0044 \\
\hline 球迷 (soccer fans) 0.0108 & 进球 (goal) 0.0048 & 内心 (heart) 0.0058 & 女儿 (daughter) 0.0034 \\
\hline 工作 (work) & 公益 (charity) & 生活记录 (life record) & 宗教 (religion) \\
\hline Topic3: & Topic18: & Topic36: & Topic13: \\
\hline 同学 (classmate) 0.0064 & 孩子 (child) 0.0351 & 婏嘴 (glutton) 0.0140 & 佛教 (Buddhism) 0.0108 \\
\hline 回家 (go home) 0.0049 & 爱心 (love) 0.0120 & 星座 (constellation) 0.0121 & 菩萨 (buddha) 0.0092 \\
\hline 心情 (mood) 0.0040 & 父母 (parent) 0.0096 & 休息 (rest) 0.0113 & 修行 (discipline) 0.0078 \\
\hline 上班 (go to work) 0.0037 & 祝福 (blessing) 0.0089 & 熊猫 (panda) 0.0061 & 众生 (beings) 0.0070 \\
\hline 吃饭 (eat) 0.0036 & 生命 (live) 0.0074 & 加油 (fighting) 0.0095 & 法师 (master) 0.0070 \\
\hline 公司 (company) 0.0029 & 传递 (delivery) 0.0074 & 睡觉 (sleep) 0.0074 & 智慧 (wisdom) 0.0065 \\
\hline
\end{tabular}

Table 4. The terms and probabilities of topics presented in Table 3.

user model, the fusion model substitutes "Topic36" for "Topic13." Table 4 details the probability of the terms for each topic in Table 3.

High-frequency topics of the three models are "training," "football game," "life thought," "family," and "work"; in the fusion model, "religion" was replaced by "life record." The high weight of the topics "training" and "football game" indicates that this user likes football or does work related to football; they are also interested in other topics, like "life thoughts," "family," "work," "charity," and "life record,"

\subsubsection{Community detection}

We detected four communities based on the relationship dataset. Figure 3 shows the population distribution of the communities' members.
As Figure 3 shows, Community 3 has the largest number of members (almost $40 \%$ of the total); the other three communities have similarly sized populations, each being around $20 \%$.

As Figure 4 shows, users in the Community 4 are mainly related with the football domain and a few users are related with the other four domains. It indicates that users from different domains are linked. There are significantly more men than women in the "football" community, indicating that male users are more interested in football. Finally, the registration date findings indicate that Weibo's popularity increased significantly in 2010 and 2011, with a high proportion of registrations in both years.

As Figure 5 shows, members of the "football" community come from different provinces. Besides Beijing, Shanghai and Guangzhou, there are many users from other regions like Liaoning, Guangdong, Shandong, Tianjin, Hubei, etc. 


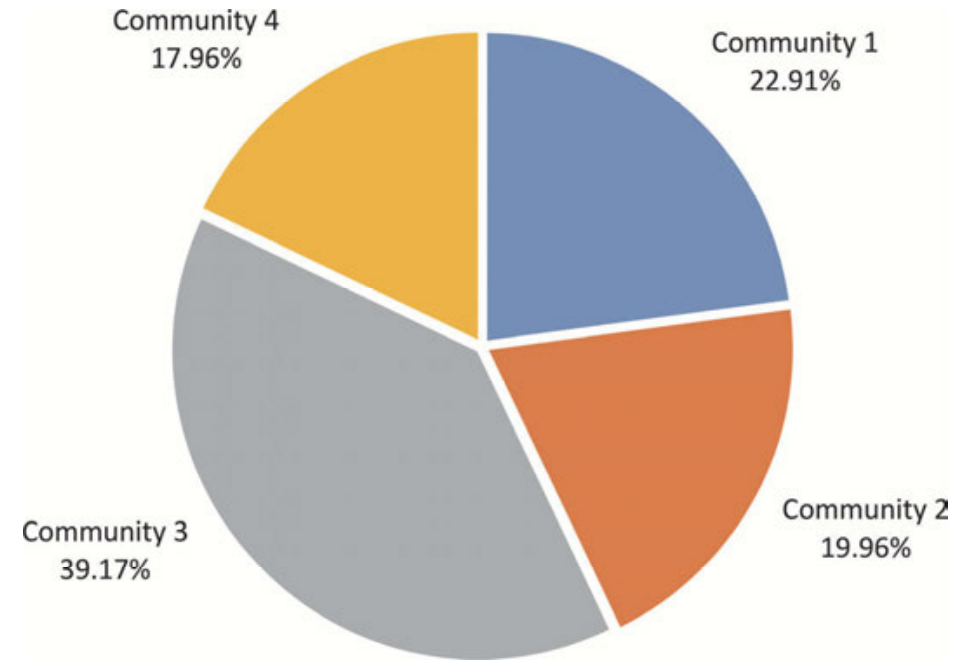

Figure 3. Community population distribution.

\section{Domain distribution}

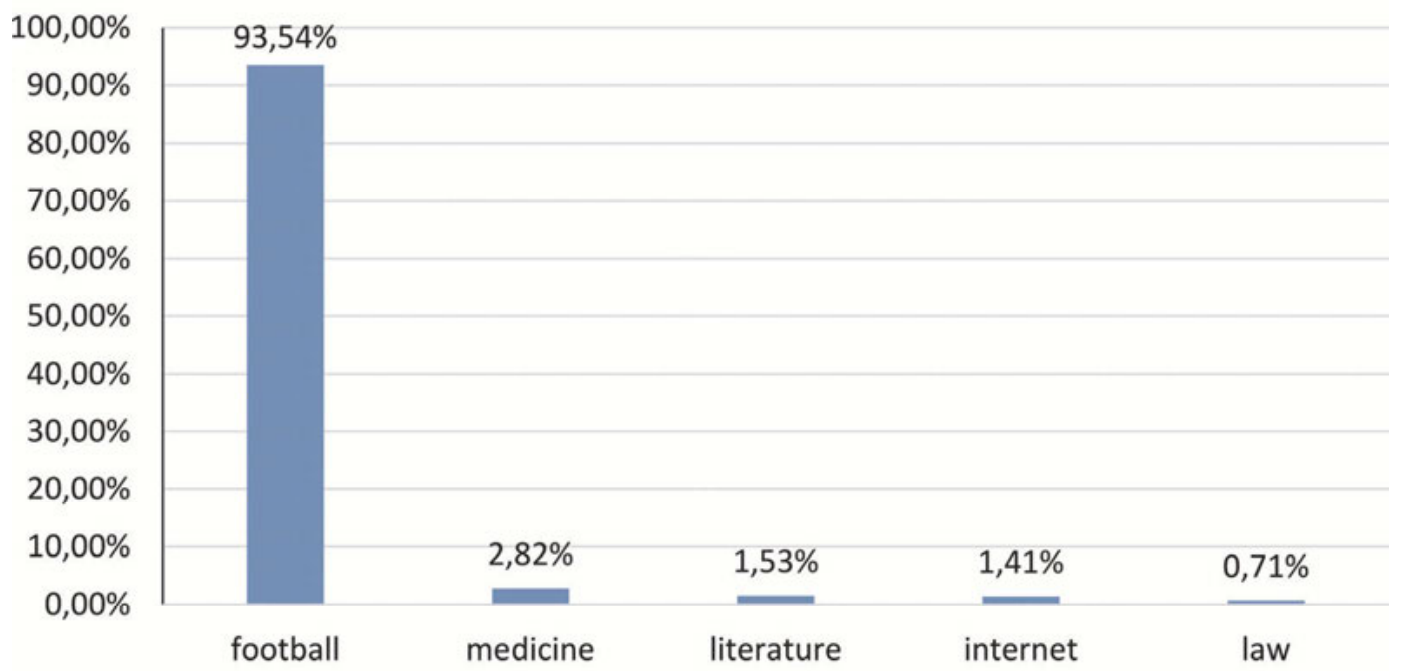

Gender distribution

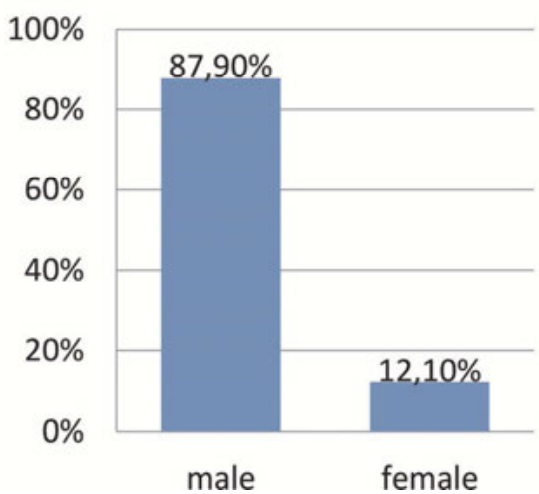

Registration date distribution

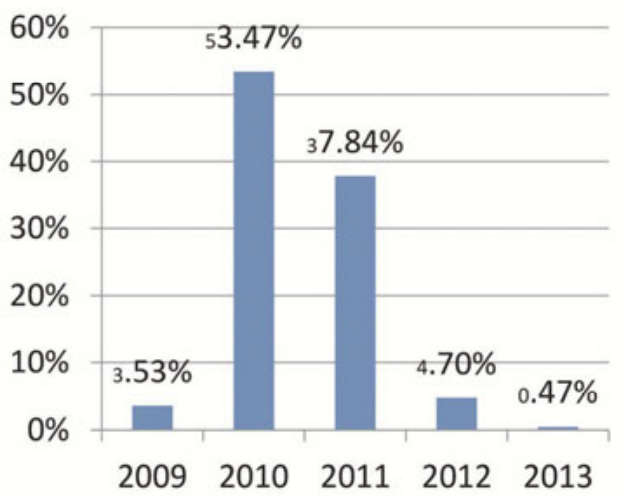

Figure 4. Domain, Gender, and Registration Date Distribution of Community 4. 


\section{Number of people}

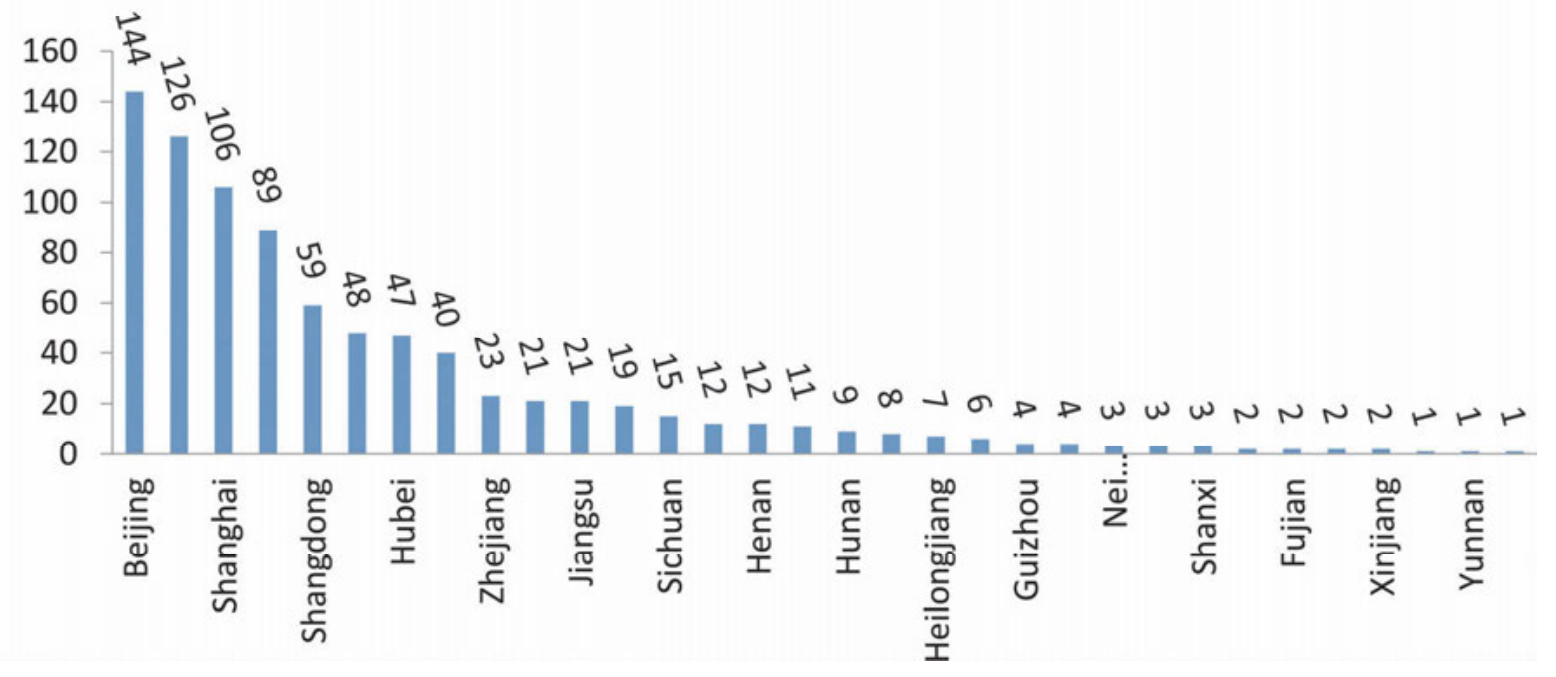

Figure 5. Province Map of Community 4.

\subsubsection{Multi-dimensional association}

In this section, we will show the relationship between community topics and hierarchical topic for the "football" community. Figure 6 shows the associations among user, community, and topic hierarchy.

User "178****763" in Sina Weibo is assigned to the "football" community from the experiment results, so we can recommend the "football" community and other members to them. Community topic 0 is closely related to first-layer topic3, which is itself closely related to secondlayer topic4, which is, in turn, closely related to third-layer topic1.
Table 5 shows the term distribution of topic0 ("football"), topic4 ("football game"), and topic1 ("domestic match"). These topics are closely related to topic0 ("football training").

For fine-grained detail on the community's interest topics, we present the third-layer topic distribution of secondlayer topic 4 in Table 6.

As Table 6 shows, the third-layer topics of second-layer topic4 are "international match," "domestic match," "player training," "football show," and "person." We can thus recommend topics in a more refined and accurate way based on the associated community and topic hierarchy. Here, we can recommend these third-layer topics for the "football"

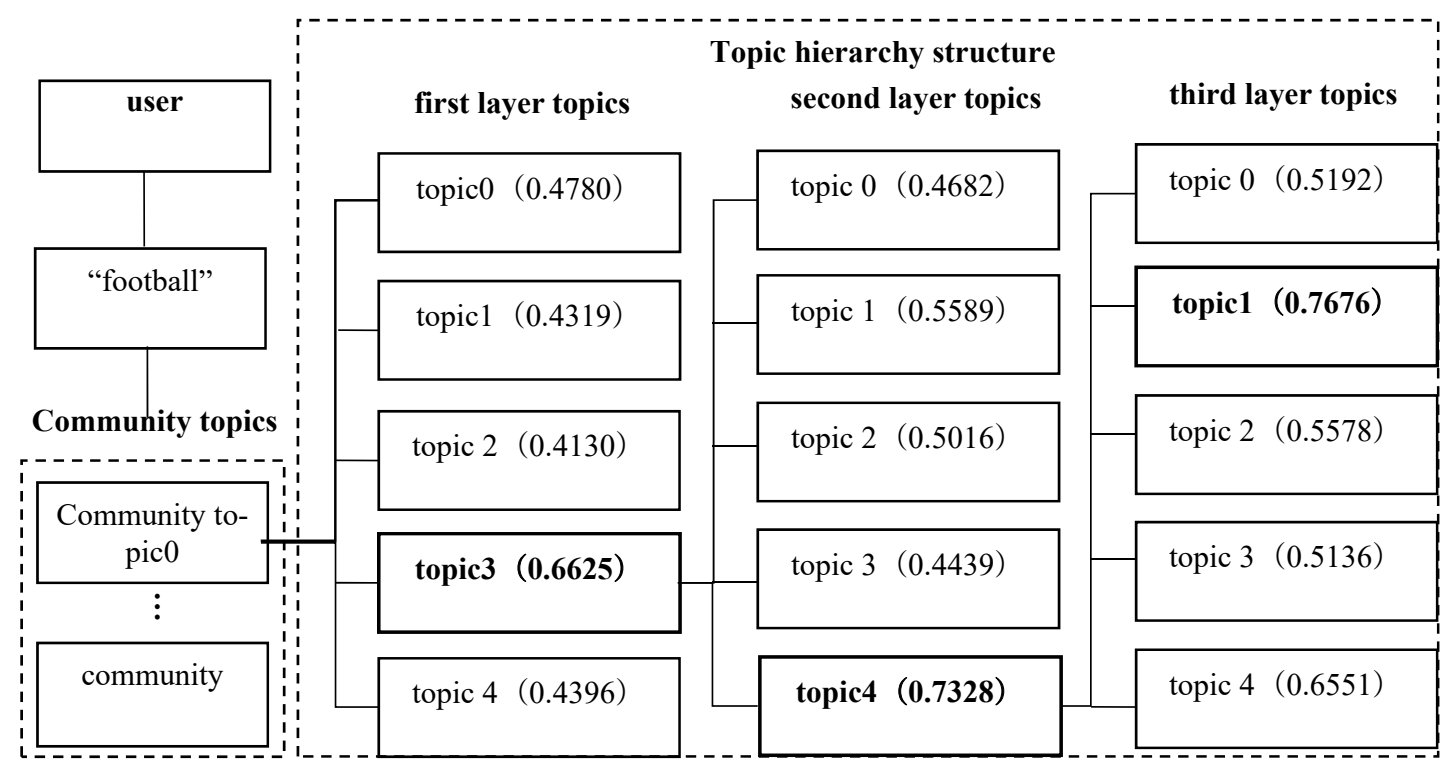

Figure 6. Associations among user, community, and topic hierarchy in the "football" community. 
Chengzhi Zhang, Hua Zhao, Xuehua Chi and Shuitian Ma. Information Organization Patterns from Online Users in a Social Network

\begin{tabular}{|c|c|c|}
\hline $\begin{array}{c}\text { First-layer topic-Topic3 } \\
\text { “足球” } \\
\text { (football) }\end{array}$ & $\begin{array}{c}\text { Second-layer topic-Topic4 } \\
\text { “足球赛事” } \\
\text { (football game) }\end{array}$ & $\begin{array}{c}\text { Third-layer topic-Topic1 } \\
\text { “国内赛事” } \\
\text { (domestic match) }\end{array}$ \\
\hline 加油 (fighting) & 足球 (football) & 比赛 (competition) \\
0.0053 & 0.0196 & 0.0369 \\
\hline 足球 (football) & 比赛 (competition) & 球迷 (football fan) \\
0.0051 & 0.0191 & 0.0211 \\
\hline 比赛 (competition) & 加油 (fighting) & 足球 (football) \\
\hline 0.0050 & 0.0161 & 0.0191 \\
\hline 回家 (go home) & 球迷 (football fan) & 球队 (football team) \\
\hline 0.0031 & 0.0088 & 0.0102 \\
\hline 妈妈 (mother) & 俱乐部 (football club) & 广州 (Guangzhou) \\
0.0027 & 0.0054 & 0.0073 \\
\hline 睡觉 (sleep) & 球队 (football team) & 联赛 (league) \\
0.0025 & 0.0054 & 0.0069 \\
\hline 孩子 (child) & 训练 (train) & 北京 (Beijing) \\
0.0025 & 0.0053 & 0.0060 \\
\hline 球迷 (football fan) & 球员 (footballer) & 青岛 (Qingdao) \\
0.0023 & 0.0048 & 0.0054 \\
\hline 爱心 (love) & 兄弟 (brother) & 主场 (home court) \\
0.0019 & 0.0047 & 0.0049 \\
\hline 兄弟 (brother) & 体育 (sports) & 上海 (Shanghai) \\
0.0019 & 0.0042 & 0.0048 \\
\hline
\end{tabular}

Table 5. Relevant topics of community topic0.

\begin{tabular}{|c|c|c|c|c|}
\hline $\begin{array}{c}\text { Topic0 } \\
\text { “世界赛事” } \\
\text { (international match) }\end{array}$ & $\begin{array}{c}\text { Topic1 } \\
\text { “国内赛事” } \\
\text { (domestic match) }\end{array}$ & $\begin{array}{c}\text { Topic2 } \\
\text { “球员训练” } \\
\text { (player training) }\end{array}$ & $\begin{array}{c}\text { Topic3 } \\
\text { “足球节目” } \\
\text { (football show) }\end{array}$ & $\begin{array}{l}\text { Topic4 } \\
\text { “风云人物” } \\
\text { (person) }\end{array}$ \\
\hline $\begin{array}{c}\text { 比赛 (competition) } \\
0.0167\end{array}$ & $\begin{array}{c}\text { 比赛 (competition) } \\
0.0369\end{array}$ & $\begin{array}{c}\text { 足球 (football) } \\
0.0288\end{array}$ & $\begin{array}{c}\text { 体育 (sports) } \\
0.0108\end{array}$ & $\begin{array}{c}\text { 加油 (fighting) } \\
0.0122\end{array}$ \\
\hline $\begin{array}{c}\text { 球员 (footballer) } \\
0.0085\end{array}$ & $\begin{array}{c}\text { 球迷 (football fan) } \\
0.0211\end{array}$ & $\begin{array}{c}\text { 教练 (coach) } \\
0.0060\end{array}$ & $\begin{array}{c}\text { 足球 (football) } \\
0.0080\end{array}$ & $\begin{array}{c}\text { 国安 (Guoan) } \\
0.0059\end{array}$ \\
\hline $\begin{array}{c}\text { 进球 (goal) } \\
0.0076\end{array}$ & $\begin{array}{c}\text { 足球 (football) } \\
0.0191\end{array}$ & $\begin{array}{l}\text { 孩子 (child) } \\
0.0058 \\
\end{array}$ & $\begin{array}{c}\text { 比赛 (competition) } \\
0.0059\end{array}$ & $\begin{array}{c}\text { 足球 (football) } \\
0.0032\end{array}$ \\
\hline $\begin{array}{c}\text { 球队 (football team) } \\
0.0075\end{array}$ & $\begin{array}{c}\text { 球队 (football team) } \\
0.0102\end{array}$ & $\begin{array}{c}\text { 训练 (train) } \\
0.0048\end{array}$ & $\begin{array}{c}\text { 上海 (Shanghai) } \\
0.0046\end{array}$ & $\begin{array}{c}\text { 女足 (women's soccer) } \\
0.0025\end{array}$ \\
\hline $\begin{array}{c}\text { 西班牙 (span) } \\
0.0061\end{array}$ & $\begin{array}{c}\text { 广州 (Guangzhou) } \\
0.0073\end{array}$ & $\begin{array}{c}\text { 运动 (sport) } \\
0.0039\end{array}$ & $\begin{array}{c}\text { 球迷 (football fan) } \\
0.0045\end{array}$ & $\begin{array}{c}\text { 青岛 (Qingdao) } \\
0.0023\end{array}$ \\
\hline $\begin{array}{c}\text { 冠军 (champion) } \\
0.0055\end{array}$ & $\begin{array}{c}\text { 联赛 (league) } \\
0.0069\end{array}$ & $\begin{array}{c}\text { 球员 (footballer) } \\
0.0038\end{array}$ & $\begin{array}{c}\text { 直播 (broadcasting) } \\
0.0041\end{array}$ & $\begin{array}{c}\text { 王永珀(Wang Yongbo) } \\
0.0022\end{array}$ \\
\hline $\begin{array}{c}\text { 皇马 (Real Madrid) } \\
0.0054\end{array}$ & $\begin{array}{c}\text { 北京 (Beijing) } \\
0.0060\end{array}$ & $\begin{array}{c}\text { 俱乐部 (football club) } \\
0.0036 \\
\end{array}$ & $\begin{array}{c}\text { 参加 (participate) } \\
0.0038\end{array}$ & $\begin{array}{c}\text { 李 帅(Li Shuai) } 818 \\
0.0017\end{array}$ \\
\hline $\begin{array}{c}\text { 巴萨 (Bass) } \\
0.0049\end{array}$ & $\begin{array}{c}\text { 青岛 (Qingdao) } \\
0.0054\end{array}$ & $\begin{array}{c}\text { 比赛 (competition) } \\
0.0035\end{array}$ & $\begin{array}{c}\text { 俱乐部 (football club) } \\
0.0037\end{array}$ & $\begin{array}{c}\text { 王晓龙 (Wang Xiaolong) } \\
0.0016\end{array}$ \\
\hline $\begin{array}{c}\text { 意大利 (Italy) } \\
0.0048\end{array}$ & $\begin{array}{c}\text { 主场 (home court) } \\
0.0049\end{array}$ & $\begin{array}{c}\text { 运动员 (athlete) } \\
0.0032\end{array}$ & $\begin{array}{c}\text { 现场 (scene) } \\
0.0031\end{array}$ & $\begin{array}{c}\text { 邵佳一(Shao Jiayi) } \\
0.0016\end{array}$ \\
\hline $\begin{array}{c}\text { 决赛 (final) } \\
0.0047\end{array}$ & $\begin{array}{c}\text { 上海 (Shanghai) } \\
0.0048\end{array}$ & $\begin{array}{c}\text { 体育 (sports) } \\
0.0032\end{array}$ & $\begin{array}{c}\text { 节目 (show) } \\
0.0028\end{array}$ & $\begin{array}{c}\text { 徐云龙(Xu Yunlong) } \\
0.0015\end{array}$ \\
\hline
\end{tabular}


community. In addition, other second-layer topics can be recommended to the community to help users access more relevant information. In short, users can easily obtain a comprehensive, in-depth picture of their topics of interest.

\subsubsection{Comparisons between different organization patterns}

There are three basic elements for information organization in this paper: topic hierarchy, user, and community. As Table 7 shows, we analyze different combinations of the main elements with respect to their information organization methods and associated advantages and disadvantages. The table also provides examples of relevant social media platforms.

As described in Table 7, for those organization models using only one element (all elements are user, hierarchical topic, and community), it is more costly for users to access information from another two sources. For those models using two elements, shortages might exist when information organization is trying to build on the missing element. For instance, user interaction is not sufficiently

\begin{tabular}{|c|c|c|c|c|}
\hline Basic Elements & Organization Model & Advantages & Disadvantages & Social Media Cases \\
\hline User & $\begin{array}{l}\text { Users in a friend } \\
\text { relationship on social } \\
\text { media can send all types } \\
\text { of messages and be fully } \\
\text { connected. }\end{array}$ & $\begin{array}{l}\text { Information is usually } \\
\text { shared through a one-to- } \\
\text { one connection and with } \\
\text { known friends, which } \\
\text { guarantees privacy. }\end{array}$ & $\begin{array}{l}\text { Obtained information } \\
\text { resources are limited to } \\
\text { the range of friends. }\end{array}$ & $\begin{array}{l}\text { Communication software } \\
\text { e.g., Tencent QQ, } \\
\text { Messenger }\end{array}$ \\
\hline $\begin{array}{l}\text { Hierarchical } \\
\text { Topic }\end{array}$ & $\begin{array}{l}\text { Information content is } \\
\text { based on entries and is } \\
\text { organized in a } \\
\text { hierarchical manner } \\
\text { according to a certain } \\
\text { classification system or } \\
\text { topic. }\end{array}$ & $\begin{array}{l}\text { Information organized in } \\
\text { a hierarchical topic } \\
\text { structure can help users } \\
\text { to quickly search for and } \\
\text { find needed knowledge. }\end{array}$ & $\begin{array}{l}\text { Classification system is } \\
\text { not clear enough; the } \\
\text { data need to be } \\
\text { maintained and updated } \\
\text { in real time. }\end{array}$ & $\begin{array}{l}\text { Internet encyclopedia } \\
\text { projects } \\
\text { e.g., Wikipedia, Baidu } \\
\text { Encyclopedia }\end{array}$ \\
\hline Community & $\begin{array}{l}\text { Users with the same } \\
\text { information needs are } \\
\text { integrated in the same } \\
\text { virtual space and } \\
\text { communicate with one } \\
\text { another within this } \\
\text { community. }\end{array}$ & $\begin{array}{l}\text { Users within the same } \\
\text { community can quickly } \\
\text { share information. }\end{array}$ & $\begin{array}{l}\text { Accessible information } \\
\text { resources are limited by } \\
\text { community themes. }\end{array}$ & $\begin{array}{l}\text { Online communities, } \\
\text { e.g., Google Groups }\end{array}$ \\
\hline $\begin{array}{l}\text { User }+ \\
\text { Hierarchical } \\
\text { Topic }\end{array}$ & $\begin{array}{l}\text { Users who seek specific } \\
\text { information will consult } \\
\text { their friends or look for } \\
\text { relevant information } \\
\text { based on the topic. }\end{array}$ & $\begin{array}{l}\text { Interaction between users } \\
\text { and information } \\
\text { acquisition can be } \\
\text { efficient. }\end{array}$ & $\begin{array}{l}\text { User interaction is not } \\
\text { sufficiently strong. }\end{array}$ & $\begin{array}{l}\text { Socialized question and } \\
\text { answer platforms, } \\
\text { e.g., Zhihu, Stack } \\
\text { Overflow }\end{array}$ \\
\hline $\begin{array}{l}\text { User + } \\
\text { Community }\end{array}$ & $\begin{array}{l}\text { Users make friends } \\
\text { gradually and } \\
\text { communities are basically } \\
\text { groups of users with a } \\
\text { common interest or goal, } \\
\text { who are also highly likely } \\
\text { to be friends. }\end{array}$ & $\begin{array}{l}\text { Convenient for users to } \\
\text { effectively achieve their } \\
\text { social goals and maintain } \\
\text { personal connections. }\end{array}$ & $\begin{array}{l}\text { Community construction } \\
\text { is affected by users' social } \\
\text { activities over social } \\
\text { media. }\end{array}$ & $\begin{array}{l}\text { Business social platforms, } \\
\text { e.g., LinkedIn, Dajie } \\
\text { Network }\end{array}$ \\
\hline $\begin{array}{l}\text { Community }+ \\
\text { Hierarchical } \\
\text { Topic }\end{array}$ & $\begin{array}{l}\text { Users within each } \\
\text { community have highly } \\
\text { personalized interactions; } \\
\text { different communities } \\
\text { have different topics that } \\
\text { can be organized in a } \\
\text { hierarchical structure. }\end{array}$ & $\begin{array}{l}\text { Users in the same } \\
\text { community can share } \\
\text { information in real time } \\
\text { and find corresponding } \\
\text { sub-communities } \\
\text { according to their own } \\
\text { information needs. }\end{array}$ & $\begin{array}{l}\text { Information sharing } \\
\text { within social media } \\
\text { communities is mainly in } \\
\text { the form of text and } \\
\text { pictures. }\end{array}$ & $\begin{array}{l}\text { Web forums } \\
\text { e.g., Tianya }\end{array}$ \\
\hline $\begin{array}{l}\text { User }+ \\
\text { Hierarchical } \\
\text { Topic }+ \\
\text { Community }\end{array}$ & $\begin{array}{l}\text { Users can obtain } \\
\text { information through } \\
\text { friendships, communities } \\
\text { to which they belong, and } \\
\text { hierarchical topics on } \\
\text { social media. }\end{array}$ & $\begin{array}{l}\text { Users can engage in } \\
\text { social behaviors, access } \\
\text { rich information sources, } \\
\text { and obtain information } \\
\text { effectively from different } \\
\text { sources. }\end{array}$ & $\begin{array}{l}\text { There might be } \\
\text { information security } \\
\text { risks. }\end{array}$ & $\begin{array}{l}\text { Social networking } \\
\text { platforms, } \\
\text { e.g., Facebook, Douban }\end{array}$ \\
\hline
\end{tabular}

Table 7. Comparisons between different information organization patterns. 
strong when community information is not considered. Therefore, the most efficient solution is to incorporate all three elements in the information organization model, enabling users to obtain information via friends, communities to which they belong, and hierarchical topics on social media.

\subsection{Conclusion}

We have described our investigation into how to organize information on social networks in a user-centered way to meet personalized needs. Our proposed method linked UGCs, users, and user communities in multi-dimensional framework.

First, we constructed a three-layer topic hierarchy based on UGCs. Second, we developed a user interests model using UGCs and relationship data, fusing the user, follower, and following models. Third, inspired by previous work on community detection, we proposed a new approach for detecting the topics of each community. Finally, we derived a multi-dimensional information organization pattern through similarities among three dimensions: the UGC topic hierarchy, user interest model, and user communities.

Our results show that the topic hierarchy is effective in providing supplementary and recommended information. Problems of spare data in user modeling can be partly solved by integrating it with the relational model. We can also help users find communities of interest using community detection. As the user modeling in this paper is not evaluated, we propose to conduct a follow-up study, in which the evaluation will involve both expert scoring and user assessment, such as user satisfaction of information recommended through platforms.

\section{References}

Agichtein, Eugene, Carlos Castillo, Debora Donato, Aristides Gionis and Gilad Mishne. 2008. "Finding Highquality Content in Social Media." In WSDM'08: Proceedings of the 2008 international conference on web search and data mining. February 11-12, 2008, California, US A. New York, NY: Association for Computing Machinery, 183-194. Doi:10.1145/1341531.1341557

Bar-Ilan, Judit and Yifat Belous. 2007. "Children as Architects of Web Directories: an Exploratory Study." Journal of the American Society for Information Science \& Technology 58: 895-907.

Bawden, David. 2006. "Users, User Studies and Human Information Behaviour." Journal of Documentation 62: 671-679.

Benevenuto, Fabrício, Tiago Rodrigues, Meeyoung Cha and Virgílio Almeida. 2009. "Characterizing User Behavior in Online Social Networks.” In IMC’09: Proceed- ings of the 9th ACM SIGCOMM Conference on Internet Measurement. November 4-6, 2009, Chicago, Illinois. New York, NY: Association for Computing Machinery, 4962. doi:10.1145/1644893.1644900

Blei, David M., Andrew Y. Ng and Michael I. Jordan. 2003. "Latent Dirichlet Allocation." J Machine Learning Research Archive 3: 993-1022

Bu, Shuqing, Huamei Liu and Guangping Wang. 2010. “ 国外近几年网络环境下知识组织理论、方法的深 化与拓展." [A Summary of Recent Research on Knowledge Organization.] 中国索引 [Journal of the China Society of Indexers] 1:2-12.

Chen, Sherry Y. and Nigel J. Ford. 1998. "Modelling User Navigation Nehaviours in a Hypermedia-based Learning System: An Individual Differences Approach.” Knowledge organization 25: 67-78.

Chen, Enhong, Yanggang Lin, Hui Xiong, Qiming Luo and Haiping Ma. 2011. "Exploiting Probabilistic Topic Models to Improve Text Categorization under Class Imbalance." Information Processing \& Management 47: 202214.

Gao, Xia and Jiancheng Guan. 2012. "Network Model of Knowledge Diffusion.” Scientometrics 90: 749-62.

Gupta, Manish, Rui Li, Zhijun Yin and Jiawei Han. 2010. "Survey on Social Tagging Techniques." ACM SIGKDD Explorations Newsletter 12: 58-72.

Hannon, John, Mike Bennett and Barry Smyth. 2010. "Recommending Twitter Users to Follow Using Content and Collaborative Filtering Approaches." In RecSys'10: Proceedings of the fourth ACM conference on Recommender systems. September 26-30, 2010, Barcelona, Spain. New York, NY: Association for Computing Machinery, 199-206. doi:10.1145/1864708.1864746

Hjørland, Birger. 2003. "Fundamentals of Knowledge Organization." Knowledge organization 30: 87-111.

Hjørland, Birger. 2014. "User-based and Cognitive Approaches to Knowledge Organization: A Theoretical Analysis of the Research Literature." Knowledge organization 40: 11-27.

Kaplan, Andreas M. and Michael Haenlein. 2010. "Users of the World, Unite! The Challenges and Opportunities of Social Media." Business Horizons 53: 59-68.

Keenan, Andrew and Ali Shiri. 2013 "Sociability and Social Interaction on Social Networking Websites.” Library Review 58: 438-450.

Kietzmann, Jan H., Kristopher Hermkens, Ian P. McCarthy, Bruno S. Silvestre. 2011. "Social Media? Get Serious! Understanding the Functional Building Blocks of Social Media." Business Horizons 54: 241-251.

Kim, Hak Lae, Simon Scerri, John G. Breslin, Stefan Decker and Hong Gee Kim. 2008. "The State of the Art in Tag Ontologies: A Semantic Model for Tagging and Folksonomies." In DC2008: Proceedings of the 
International Conference on Dublin Core and Metadata Applications 2008. September 22-26, 2008, Berlin, Germany. Singapore: Dublin Core Metadata Initiative, 128-137.

Kwak, Haewoon, Changhyun Lee, Hosung Park and Sue Moon. 2010. "What is Twitter, a Social Network or a News Media?" In WWW2010: Proceedings of the 19th international conference on World Wide Web. April 26-30, 2010, Raleigh, USA. New York, NY: Association for Computing Machinery, 591-600. doi: 10.1145/1772690.1772751

Li, Jinhai, Changlin Mei and Yuejin Lv. 2013. "Incomplete Decision Contexts: Approximate Concept Construction, Rule Acquisition and Knowledge Reduction." International Journal of Approximate Reasoning 54: 149-165.

Maia, Marcelo, Jussara Almeida and Virgílio Almeida. 2008. "Identifying User Behavior in Online Social Networks." In SocialNets'08: Proceedings of the 1st Workshop on Social Network Systems. April 1, 2008, Glasgow, Scotland, UK. New York, NY: Association for Computing Machinery, 1-6.

Mathes, Adam. 2004. 'Folksonomies: Cooperative Classification and Communication through Shared Metadata." http://www.adammathes.com/academic/com puter -mediated-communication/folksonomies.html.

Munk, Timme Bisgaard and Kristian Mork. 2007. "Folksonomy, the Power Law \& the Significance of the Least Effort." Knowledge organization 34: 16-33.

Newman, Mark EJ and Michelle Girvan. 2004. "Finding and Evaluating Community Structure in Networks." Physical review E 69: 026113.

Noruzi, Alireza. 2006. "Folksonomies: (Un) controlled Vocabulary?” Knowledge organization 33: 199-203.

Potnis, Devendra. 2011. "Folksonomy-based User-centric Information Organization Systems." International Journal of Information Studies 3: 31-43.

Qiang, Bi, and Wang Yu. 2013. "Fronts and Hotspots of the Application Research on Folksonomy Abroad." (In Chinese) Data Analysis and Knowledge Discovery 29: 36-42.

Raghavan, Usha Nandini, Réka Albert, and Soundar Kumara. 2007. "Near Linear Time Algorithm to Detect Community Structures in Large-scale Networks." Physical Review E Statistical Nonlinear \& Soft Matter Physics 76: 036106.

Steyvers, Mark, Padhraic Smyth, Michal Rosen-Zvi and Thomas Griffiths. 2004. "Probabilistic Author-topic Models for Information Discovery." In KDD'04: Proceedings of the tenth ACM SIGKDD international conference on Knowledge discovery and data mining. August 22-25, 2004, Seattle, Washington, USA. New York, NY: Association for Computing Machinery, 306-315. doi:10.1145/1014052. 1014087

Stutzman, Frederic. 2006. "An Evaluation of Identity-sharing Behavior in Social Network Communities." International Journal of Performance Arts \& Digital Media 3: 10-18.
Treem, Jeffrey W. and Paul M. Leonardi. 2012. "Social Media Use in Organizations: Exploring the Affordances of Visibility, Editability, Persistence, and Association." Social Science Electronic Publishing 36: 143-189.

Tu, Cunchao, Zhiyuan Liu, Huanbo Luan and Maosong Sun. 2015. "PRISM: Profession Identification in Social Media." ACM Transactions on Intelligent Systems and Technology 8, no. 6: 1-16.

Van Damme, Céline, Martin Hepp, and Katharina Siorpaes. 2007. "Folksontology: An Integrated Approach for Turning Folksonomies into Ontologies." Paper presented at Bridging the Gap between Semantic Web and Web 2.0 (SemNet 2007), at the 4th European Semantic Web Conference. http://citeseerx.ist.psu.edu/ viewdoc/summary?doi=10.1.1.379.5516

Ming, Zhao Yan, Jintao Ye, and Tat Seng Chua. 2014. "A Dynamic Reconstruction Approach to Topic Summarization of User-generated-content." In CIKM '14: Proceedings of the 23rd ACM International Conference on Conference on Information and Knowledge Management. November 03-07, 2014, Shanghai, China. New York, NY: Association for Computing Machinery, 311-320. doi:10.1631/FITEE. 1500402

Zhang, Wei, Jia-yu Zhuang, Xi Yong, Jian-kou Li, Wei Chen and Zhe-min Li. 2017. "Personalized Topic Modeling for Recommending User-generated Content." Frontiers of information technology \& electronic engineering 18: 708-718.

Zhou, Xiaoying. 2010. “知识链接的发展阶段、发展动 因和类型特征分析.” [Studies on Development Phases, Development Motivation, Type and Characteristic of knowledge Linkage.] 图书情报工作 [Library and Information Service] 54: 36-40.

Zhu, Xingwei, Zhao-Yan Ming, Zhao-Yan Ming, ZhaoYan Ming. 2013. "Topic Hierarchy Construction for the Organization of Multi-source User Generated Contents." In SIGIR'13: Proceedings of the 36th international ACM SIGIR conference on Research and development in information retrieval. July 28 - August 01, 2013, Dublin, Ireland. New York, NY: Association for Computing Machinery, 233-242. doi: 10.1145/2484028.2484032

Zhu, Xingwei, Zhao-Yan Ming, Yu Hao, Xiaoyan Zhu, Tat-Seng Chua. 2014. "Customized Organization of Social Media Contents Using Focused Topic Hierarchy." In CIKM '14: Proceedings of the 23rd ACM International Conference on Conference on Information and Knowledge Management. November 03-07, 2014, Shanghai, China. New York, NY: Association for Computing Machinery, 1509-1518. doi:10.1145/2661829.2661896 
Chengzhi Zhang, Hua Zhao, Xuehua Chi and Shuitian Ma. Information Organization Patterns from Online Users in a Social Network

Appendix: The sample of UGC topic hierarchy construction

The first layer

\begin{tabular}{|c|c|c|c|c|}
\hline "文学"(literature) & “法律”(law) & “医疗"(medical) & “足球”(football) & “互联网”(internet) \\
\hline Topic0 : 0.2707 & Topic1 : 0.1894 & Topic2 $: 0.1238$ & Topic3 : 0.2557 & Topic4 : 0.1604 \\
\hline 人生(life) 0.0049 & 律师 (lawyer) 0.0203 & 孩子(child) 0.0118 & 加油(fighting) 0.0053 & 手机(phone) 0.0076 \\
\hline 生活(live) 0.0048 & 法律(law) 0.0049 & 医院(hospital) 0.0111 & 足球(football) 0.0051 & 活动 (activity) 0.0053 \\
\hline 作家(writer) 0.0041 & 社会(society) 0.0049 & 治疗(treat) 0.0110 & 比赛(competition) 0.0050 & 公司(company) 0.0052 \\
\hline 故事(story) 0.0038 & 国家(country) 0.0044 & 宝宝(baby) 0.0080 & 回家(back home) 0.0031 & 发布(release) 0.0044 \\
\hline 小说(fiction) 0.0034 & 美国(America) 0.0040 & 患者(sufferer) 0.0075 & 妈妈 (mother) 0.0027 & 体验(experience) 0.0041 \\
\hline 电影(film) 0.0034 & 政府(government) 0.0035 & 手术(operation) 0.0058 & 上海(Shanghai) 0.0026 & 产品(product) 0.0034 \\
\hline 作品(works) 0.0030 & 新闻(news) 0.0031 & 检查(examination) 0.0050 & 睡觉(sleep) 0.0025 & 升级 (upgrade) 0.0032 \\
\hline 作者(author) 0.0026 & 媒体(media) 0.0026 & 女性(female) 0.0038 & 孩子(child) 0.0025 & 微信(wechat) 0.0032 \\
\hline 出版(publish) 0.0020 & 法院(court) 0.0021 & 门诊(clinic) 0.0038 & 球迷(football fans) 0.0023 & 互联网(internet) 0.0031 \\
\hline 文学(literature) 0.0019 & 法官(judge) 0.0018 & 病人 (patient) 0.0035 & 鮧嘴(greedy) 0.0021 & 功能(function) 0.0030 \\
\hline \multicolumn{5}{|l|}{ The second layer } \\
\hline “专家”(expert) & “日常休养” & “外科"（surgery） & “女性医疗” & “饮食”(diet) \\
\hline Topic0: 0.2269 & (daily maintenance) & Topic2: 0.1451 & (women's health care) & Topic4: 0.1627 \\
\hline 医院(hospital) 0.0219 & Topic1:0.2759 & 治疗(treat) 0.0180 & Topic3: 0.1894 & 宝宝(baby) 0.0149 \\
\hline 北京(Beijing) 0.0082 & 宝宝(baby) 0.0089 & 效果(effectment) 0.0058 & 治疗(treat) 0.0213 & 食物(food) 0.0126 \\
\hline 患者(sufferer) 0.0079 & 妈妈 (mother) 0.0063 & 皮肤(skin) 0.0055 & 检查(check) 0.0130 & 维生素(vitamine) 0.0060 \\
\hline 病人 (patient) 0.0070 & 运动(sport) 0.0055 & 疼痛(pain) 0.0053 & 患者(suffer) 0.0124 & 饮食(diet) 0.0060 \\
\hline 医疗 (medical) 0.0061 & 生活(live) 0.0050 & 患者(sufferer) 0.0053 & 医院(hospital) 0.0093 & 营养(nutrition) 0.0054 \\
\hline 大夫(doctor) 0.0050 & $\begin{array}{l}\text { 身体(body) } 0.0049 \\
\text { 家长(patriarch) } 0.0040\end{array}$ & 眼睛(eye) 0.0045 & $\begin{array}{l}\text { 女性(female) } 0.0089 \\
\text { 疾病(disease) } 0.0077\end{array}$ & 食品(food) 0.0042 \\
\hline 教授(professor) 0.0049 & 父母(parents) 0.0039 & 针炎(acupuncture) 0.0038 & 子宫(womb) 0.0076 & 水果(fruit) 0.0039 \\
\hline 专家(expert) 0.0047 & 慰问 ( condole) 0.0032 & 中药(chineseherb) 0.0033 & 症状(symptom) 0.0075 & 母乳(breast milk) 0.0038 \\
\hline 门诊(clinic) 0.0041 & 生病(ill) 0.0030 & 脱发(alopecia) 0.0030 & 手术(operation) 0.0073 & 牛奶(milk) 0.0032 \\
\hline 协和(Concord hospital) 0.0041 & 睡眠(sleep) 0.0029 & 按摩(massage) 0.0030 & 孩子(child) 0.0072 & 蔬菜(vegetable) 0.0031 \\
\hline \multicolumn{5}{|l|}{ The third layer } \\
\hline “备㭆”(pregnancy) & “富贯病”(affluenza) & “就诊”(vis.) & “育婴”(infant-raising) & “孥检”(pregnancy test) \\
\hline Topic0: 0.1594 & Topic1: 0.1974 & Topic2: 0.2447 & Topic3: 0.1993 & Topic4: 0.1992 \\
\hline 女性(female) 0.0294 & 糖尿病(diabetes) 0.0116 & 治疗(treat) 0.0311 & 治疗(treat) 0.0225 & 胎儿(fetus) 0.0218 \\
\hline 子宫(womb) 0.0255 & 疾病(disease) 0.0113 & 患者(sufferer) 0.0284 & 孩子(child) 0.0171 & 宝宝(baby) 0.0217 \\
\hline 治疗(treat) 0.0156 & 高血压(hypertension) 0.01 & 门诊(clinic) 0.0235 & 感染(infect) 0.0152 & 孩子(child) 0.0178 \\
\hline 医院(hospital) 0.0151 & 患者(suffer) 0.0084 & 手术(operation) 0.0204 & 药物(medicine) 0.0120 & 孕妇 (gravida) 0.0160 \\
\hline 月经(menstruation) 0.0134 & 治疗(treat) 0.0079 & 检查(check) 0.0125 & 症状(symptom) 0.0117 & 怀孥(pregnant) 0.0158 \\
\hline 宫颈(cervix) 0.0119 & 饮食(diet) 0.0079 & 加号(plus) 0.0121 & 感冒(cold) 0.0110 & 检查(check) 0.0156 \\
\hline 肌瘤(myoma) 0.0118 & 因素(factor) 0.0073 & 申请(apply) 0.0111 & 咳濑(cough) 0.0098 & 发育(growth) 0.0137 \\
\hline 检查(check) 0.0115 & 控制(control) 0.0072 & 医院(hospital) 0.0100 & 宝宝(baby) 0.0097 & 分婏(childbirth) 0.0095 \\
\hline 症状(symptom) 0.0112 & 血压(blood) 0.0067 & 病人 (patient) 0.0096 & 医院(hospital) 0.0089 & 妊娠(gestation) 0.0089 \\
\hline 不孕(sterility) 0.0093 & 预防(prevent) 0.0058 & 诊断(diagnose) 0.0076 & 疫苗(vaccine) 0.0080 & 出生(birth) 0.0059 \\
\hline
\end{tabular}

